\title{
Investigation of energy dissipation and flow regime over various forms of stepped spillways
}

Shimal Mero ${ }^{1}$ and Steve Mitchell ${ }^{2}$

${ }^{1}$ Assistant Lecturer, Department of Civil Engineering, University of Duhok, Iraq

${ }^{2}$ School of Civil Engineering and Surveying, University of Portsmouth Portsmouth PO1 3AH, UK

Corresponding Author: steve.mitchell@port.ac.uk tel +44 2392842424 


\section{Abstract}

The efficient operation of reservoirs relies on efficient release of water during flooding, requiring a good understanding of spillway hydraulics. Some experiments were conducted in a laboratory flume on a stepped spillway model with moderate slope (26.6ㅇ) for discharges up to $0.0121 \mathrm{~m}^{3} / \mathrm{s}$. Using regular uniform horizontal steps of $5 \mathrm{~cm}$ height, several new step configurations including inclined and horizontal curved steps with and without reflector blocks were used. The energy losses over a horizontal stepped spillway were compared with those obtained in a number of previous studies, and with the results obtained for the new step configurations. Good agreement was shown with previous results for horizontal steps, and the inclined and horizontal curved steps dissipated about twice as much energy as the horizontal steps. The results highlight the importance of considering a variety of step forms in spillways where flows are unpredictable and energy dissipation is important.

\section{Keywords}

Flow pattern, Stepped spillway, inclined stepped spillway, horizontal curved stepped spillway, Reflector blocks, Energy dissipation, Residual energy.

\section{List of notation}

$\theta \quad$ Stepped spillway slope in degrees;

B Channel width $(\mathrm{m})$

$E_{L} \quad$ Total energy loss: $E_{L}=E_{0}-E_{1}$ (expressed in $m$ )

$E_{0} \quad$ Energy at the inlet section (upstream section; $m$ );

$E_{1} \quad$ Energy at the downstream section $(m)$

$\mathrm{E}_{\mathrm{L}} / \mathrm{E}_{0}$ Energy dissipation rate;

$\mathrm{E}_{1} / \mathrm{y}_{\mathrm{c}} \quad$ Dimensionless residual energy;

$y_{0} \quad$ Upstream clear water flow depth $(m)$;

$y_{1} \quad$ Downstream clear water flow depth $(m)$;

$y_{c} \quad$ Critical flow depth $(m): y_{c}=\left(q^{2} / g\right)^{1 / 3}$;

$\mathrm{y}_{\mathrm{c}} / \mathrm{h} \quad$ Critical non dimensional depth;

$\mathrm{H}_{\mathrm{dam}} \quad$ Dam height (crest height) (m);

h Vertical step height $(\mathrm{m})$;

Q Water discharge $\left(\mathrm{m}^{3} / \mathrm{s}\right)$;

q Water discharge per unit width $\left(\mathrm{m}^{2} / \mathrm{s}\right), \mathrm{q}=\mathrm{Q} / \mathrm{B}$;

$v_{1} \quad$ Downstream flow velocity $(\mathrm{m} / \mathrm{s})$;

$v_{0} \quad$ Upstream average flow velocity $(\mathrm{m} / \mathrm{s})$ 


\section{Introduction}

Concerns related to the effects of unpredictably high flows entering reservoirs, especially in light of possible increased rainfall intensities, have led to renewed general interest in reservoir spillway design. A spillway is a hydraulic structure usually constructed as a part of an overflow structure adjacent to the downstream face of a dam wall. Of the many available forms (Novak et al., 2007), a stepped spillway generally has a profile forming the bed of a steep open channel comprising a series of abrupt drops. The purpose of the steps is to increase the amount of energy dissipation in the spillway while at the same time achieving the drop in water level required of such structures. Rather than using a straight vertical drop or an inclined chute, the steps are designed to replace any large drop in height by a series of smaller drops. Stepped spillways work as macro roughness elements and provide high flow resistance. Each step dissipates a considerable amount of kinetic energy and the rate of energy dissipation increases over each step. Large energy dissipaters such as stilling basins at the toe of the spillways are not always essential, or can be reduced in size, when a stepped spillway is used (Boes \& Hager, 2003; Felder \& Chanson, 2009). Furthermore, cavitation problems that commonly occur on sloping spillways are reduced thanks to the aerated flows that occur on stepped spillways (Chamani \& Rajaratnam, 1999).

The majority of previous experiments were conducted on horizontal stepped spillways in order to quantify the rate of energy dissipation and to produce design guidelines (Chanson \& Toombes, 2001; Chanson, 1995, 2001; Essery \& Horner, 1978). Sorensen (1985) was among the first to note that much work remained, and still remains, to be done in terms of optimising the design of the steps to maximise spillway efficiency for given layouts and flow conditions. However, some prototype spillways have been used with non-uniform step heights (see Chanson 2001), and their long service indicates the soundness of this design. However, the non-uniform step height has been shown to yield some flow instabilities and shock waves as reported by Toombes \& Chanson (2008) in the nappe flow regime and by Thorwarth \& Köngeter (2006) for pooled stepped spillways. In the present study, the effects of new step configurations on the flow pattern down a stepped spillway, the energy dissipation rate, and the residual energy at the toe of the spillway, were all tested systematically for a range of discharges. The aim of this study was to assess the effects of inclined and curved steps with and without reflectors on the rate of energy dissipation, residual energy and flow pattern using the same facility with the same moderate slope $(1 \mathrm{~V}: 2 \mathrm{H})$ to investigate the impact of step shape on energy dissipation. 


\section{Experimental Facility and Instrumentation}

The experimental study was conducted in the School of Civil Engineering and Surveying at the University of Portsmouth, UK. The experiments were carried out in a hydraulic flume $4 \mathrm{~m}$ long, $0.296 \mathrm{~m}$ wide and $320 \mathrm{~mm}$ deep. Five different step configurations with the same overall slope $\left(26.6^{\circ}\right)$ and step height $(\mathrm{h}=0.05 \mathrm{~m})$ were tested, with the precise aim of assessing the influence of step shape on energy dissipation. The test section consisted of a broad-crested weir $(0.296$ $\mathrm{m}$ wide, $0.1 \mathrm{~m}$ long, with upstream sharp corner) followed by five steps. With the same $26.6^{\circ}$ slope, five different step configurations were used in five different models for flow pattern and energy dissipation rate, all of which were tested systematically with several different flow rates. All step configurations had the same height and length, which were 5 and $10 \mathrm{~cm}$ respectively, as illustrated in Fig. 1. The first configuration (see Fig. 1.a) had five horizontal smooth steps, as investigated in many previous studies; the results of having this type of step could be compared with previous studies using the same chute slope, and also with the results obtained from the new step configurations used in the current study. The base model was constructed with flat steps, which were then used as the base model for all other step configurations, all other step configurations being fixed to this flat step model. The second step configuration (Fig. 1b) used five inclined steps each equal to the channel width (the height of each inclined step was $5 \mathrm{~cm}$ on one side of the channel and zero on the other). The steps were alternately opposite-facing, as shown in the figure. The third configuration (Fig. 1C) used five curved steps, which apart from being curved had the same dimensions as the second form. The fourth (Fig. 1d) and fifth (Fig. 1e) configurations used the same step arrangement as the second and the third but the width was $13 \mathrm{~cm}$ (less than channel width), with middle reflector blocks. The dimensions of the reflector blocks were (height $=5 \mathrm{~cm}$, length $=10 \mathrm{~cm}$ and width $=3.5 \mathrm{~cm}$ ). In these cases the height at each side was $5 \mathrm{~cm}$ tapering to zero in the middle, or the other way around.

During the experiments, the average flow velocity upstream and downstream of the spillways was measured using an electromagnetic flow meter (Valeport, Model 801 [Flat] EM Flow Meter). A point gauge tool was used to record the flow depth at the upstream section, enabling the flow rates to be calculated. The experiments were conducted for a wide range of discharges between 0.00213 and $0.0121 \mathrm{~m}^{3} / \mathrm{s}$.

\section{Results and Discussion}

\subsection{Analysis of flow Patterns on Flat step configuration}

The results of this experiment show that nappe flow (Fig.2a) occurred for a discharge of $0.00563 \mathrm{~m}^{3} / \mathrm{sec}$, which corresponds to a critical depth of $\mathrm{y}_{\mathrm{c}}=3.33 \mathrm{~cm}$. The corresponding critical nondimensional value $y_{c} / h=0.666$. The experimental results also show that transitional 
flow (Fig.2b) was observed when the flow rate was $0.00684 \mathrm{~m}^{3} / \mathrm{sec}$, which corresponds to a critical depth of $y_{c}=3.79 \mathrm{~cm}$. The corresponding critical nondimensional value $y_{c} / h=0.758$. Skimming flow (Fig.2c) over the flat stepped spillway occurred at a flow rate of $0.01211 \mathrm{~m}^{3} / \mathrm{sec}$, which corresponds to a value of critical depth of $y_{c}=5.54 \mathrm{~cm}$. The corresponding nondimensional value $\mathrm{y}_{\mathrm{c}} / \mathrm{h}=1.108$.

The values of $y_{c} / h$ for all flow regimes on flat steps were compared with the results of the empirical equations produced in previous studies. The value $(\mathrm{h} / \mathrm{l}=0.5)$ was substituted in the empirical equations used by other authors for these flows in order to allow appropriate comparisons to be made by producing the upper and lower limits of the flow regimes $\left(y_{d} / h\right)$. A summary of the flows found in this study, also showing the results of previous studies is presented in Table 1.

Several flow rates were used, and the flow regimes seen in this study lay between the limits produced by almost all previous studies. While the empirical equations used in previous studies might not be derivable from models with the same step geometry and chute spillway as those used in this study, nevertheless applying the height and length of the steps used in this study should yield results that are of the same order of magnitude to ours. At any rate this is the only way of comparing our model with previous models with different geometries.

These experiments produced a nappe flow regime $\left(\mathrm{y}_{\mathrm{c}} / \mathrm{h}\right)$ that was lower than the upper limit for nappe flow produced in almost all previous studies except for that of Chinnarasri \& Wongwises (2004), and Chanson \& Toombes (2004). The transitional flow regime seen in these experiments was between the values seen in most previous studies except for Yasuda et al. (2001) and Chinnarasri \& Wongwises (2004). Our values for skimming flow were higher than the lower limits found in all previous studies, see Table 1.

These experiments were carried out in a comparatively small flume based on a small model, while the majority of previous studies were carried out on larger models e.g, $h=10 \mathrm{~cm}, \mathrm{l}=20 \mathrm{~cm}$, and $\mathrm{w}=1 \mathrm{~m}$; nevertheless the results from the above comparison of flow regimes on a flat step model show that all flow regimes of this study occurred for values of $y_{c} / h$ that lay in between the upper and lower limits of the values in almost all the previous studies. This could have been because in this experiment we used a step geometry similar to the previous step geometries, and possibly also because a critical chute slope was used, as it was in some of the previous studies. There was nevertheless some disagreement between the results of this experiment and those obtained in a few of the previous studies, as discussed in Section 4.4. However, based on these results it can be concluded that these experimental results are reliable, providing a degree of confidence in the methods described. 


\subsection{Analysis of flow patterns over the new step configurations}

The flow patterns over all the new step configurations were observed for the full range of possible discharges, and several observations were made for each discharge. Because the step form was either inclined or curved, the height of each step was not constant. As a consequence, the results for the flow patterns cannot be presented in relation to the critical nondimensional value $\left(\mathrm{y}_{\mathrm{c}} / \mathrm{h}\right)$ as it can for flat steps. The flow pattern must be analysed and presented in relation to flow rates and compared to the flow pattern on flat steps. In this section we discuss the flow patterns over the new step configurations with the same flow rates that cause the three flow regimes for flat steps.

Having investigated the flow pattern for the flat steps and for all the new step configurations, we observed three flow regimes for the flat step, which occurred for the three flow rates mentioned above. The same flow patterns were observed for the new step configurations used in the experiments. The nappe flow regime was observed on the flat steps for a flow rate of 0.00563 $\mathrm{m}^{3} / \mathrm{sec}$, but it did not appear on the new step forms for the same flow rate. The transitional flow regime occurred on the flat steps at a flow rate of $0.00684 \mathrm{~m}^{3} / \mathrm{sec}$ but was not observed on the new step forms at all, possibly because the new step configurations had different step geometries. In all cases the water was divided into two parts, with one part flowing straight downstream as in the flat step, and the other part flowing either to the sidewalls or to the reflector blocks that were oriented perpendicular to the main flow, see Fig. 3. The secondary flow produced in this way hit either the sidewalls or the reflectors and produced a hydraulic jump on the same step, while the main flow generated a hydraulic jump on the subsequent step. The two parts of the flow then collided on the next step. In this way the hydraulic jump generated by the main part of the flow disappeared, the flow was disturbed, and the hydraulic jumps became drowned, with more air bubbles becoming entrained.

All these new step configurations were used for the same purpose. Horizontally inclined steps with and without reflected blocks had the same height. The width of the steps without reflectors was equal to the flume width $(0.3 \mathrm{~m})$, while the steps with reflectors were less than half the width of the flume. Therefore, the shorter steps had a steeper slope. It was found that the steps with a steeper horizontal slope (steps with reflectors) directed more water to the sides, either to the sidewalls or reflector blocks, and caused more disturbance to the flow, producing more chaotic flow regimes. The same logic applies for the horizontally curved steps, implying that shorter steps have a stronger curvature.

All the above flow patterns were observed for all the new step configurations, when the total length of the model was $0.6 \mathrm{~m}$, longer than that of the base model $(0.5 \mathrm{~m})$. To allow for this we also observed the flow patterns over the new step forms without the last step. We found that the model length did not affect the flow pattern because all the flow actions, including the hydraulic 
jump, inception point, air entrainment, turbulence and splashing occurred upstream of the last step, and in any case all the previous studies focused on the flow patterns that occurred before the last step. This is most likely because the flow produces a given velocity until it arrives at the last step, and the last step cannot change its behaviour.

During the experiments it was further noted that the flow pattern over the new step configurations varied in a wavelike form over the step width, implying that the flow surface on one side of the step differed from that on other side. This might be because the step height varied laterally and the flow surface took the same form as the steps, especially at high flow rates. In consequence, all flow regimes, nappe, transition and skimming flow were observed on the same step for any flow rate

\section{Energy dissipation}

\subsection{Flat step configuration}

It is important to quantify both the rate of energy dissipation and the residual energy over the stepped spillway. Both quantities were estimated for all step configurations from the energy between the inlet in the approach channel of the spillway $E_{0}$, and the downstream tail water $E_{1}$. The required data for $E_{0}, E_{1}$ and $E_{L} / E_{0}$ were calculated based upon flow depth and velocity measurements. $E_{\mathrm{L}} / \mathrm{E}_{0}$ expresses the proportion of total energy loss along the stepped spillway relative to the upstream total head $\left(E_{0}\right)$; the following equations were used in the energy calculation.

$$
\begin{aligned}
& E_{0}=H_{d a m}+y_{c}+\frac{v_{c}^{2}}{2 g}=H_{d a m}+1.5 y_{c} \\
& E_{1}=y_{1}+\frac{v_{1}^{2}}{2 g} \\
& E_{L}=E_{0}-E_{1}
\end{aligned}
$$

For the energy dissipation rate on the flat step, the data are presented in Fig. 4 as a function of the dimensionless term $\mathrm{H}_{\mathrm{dam}} / \mathrm{y}_{\mathrm{c}}$. The value of $\mathrm{H}_{\mathrm{dam}} / \mathrm{y}_{\mathrm{c}}$ decreases as the discharge increases. In this figure, the present data for the flat steps are compared with the experimental data from previous studies with the same chute slope $\left(\theta=26.6^{\circ}\right)$, but where the step dimensions are not generally the same. In this experiment we found that the energy dissipation rate increases with increasing $\left(\mathrm{H}_{\mathrm{dam}} / \mathrm{y}_{\mathrm{c}}\right)$, which means that the energy dissipation rate decreases with increasing discharge, which is consistent with results from earlier studies of stepped spillways (Chanson, 
1995; Chanson \& Toombes, 2001). The present study showed a higher rate of energy dissipation on the flat stepped spillway for low flow rates. This too is similar to the results of previous investigations. According to Bung (2011), friction and thus energy dissipation is not related to step height.

\subsection{All step configurations}

The energy dissipation rate decreased when the discharge increased for all the new step configurations, as mentioned in the earlier studies of stepped spillways by Chanson (1995) and Chanson \& Toombes (2001). Furthermore, the energy dissipation rate on all the new step configurations were in close agreement at low discharge. At high discharge, however, the inclined and curved steps with the reflector blocks dissipated about twice as much energy as the flat steps, the curved steps without reflectors dissipated less energy than the flat steps, and the inclined steps without reflectors dissipated slightly more energy than the flat steps, see Fig. $5 a \& b$. These figures show the energy dissipation rate on the flat and all the new step configurations with and without reflector blocks, and with and without the last step. In general, the energy dissipation rate on the new step configurations without the last step was much higher when the last step was included, especially for the new step configurations with reflectors and at high discharge (see Fig. 5b).

As previously discussed, all the new step configurations operated in similar ways in terms of the hydraulics with or without reflector blocks, either by dividing and disturbing the flow, increasing the flow depth, decreasing the flow velocity, or increasing the air entrainment on the steps in order to increase the energy dissipation rate. It is clear that the steps with reflectors are shorter and have steeper slopes (in the case of the inclined forms) and higher curvature (in case of the curved forms). The steps with reflector blocks also have more reflective faces than the steps without reflectors, and these are used to reflect the water that flows horizontally and organise the flow of water over the steps. For these reasons the energy dissipation rate for the inclined and curved steps with reflectors is much higher than for the same steps without reflectors, as shown in Fig. $5 a$ \& b.

The observations of dimensionless residual energy $E_{1} / y_{c}$ at the downstream toe are shown in Fig. $6 a \& b$, as a function of the critical nondimensional value $\left(y_{c} / h\right)$. Some differences in residual energy were observed for the different step configurations. At higher flow rates, the highest residual energy was achieved for the curved and inclined steps without reflectors, and the flat steps, while the inclined and curved steps with reflectors exhibited a lower residual energy. Again the residual energy in the cases of the new step configurations without the last step was always lower with the last step for the same discharge. The lowest residual energy was observed on inclined and curved steps with reflectors and without the last step, as shown in 
Fig. 6b. Residual energy was decreased by increasing the steps' horizontal slope and curvature as well as introducing reflectors. The inclined and curved steps were used to increase the energy dissipation by disturbing and dividing the flow on each step, increasing the flow depth and decreasing the flow velocity on each step, and increasing the air entrainment.

\subsection{Discussion of energy dissipation}

During these experiments, it was found that the energy dissipation rate on the flat steps was increased by reducing the flow rate (Fig. 7), which is consistent with the results of previous studies. This might be because the step height is fixed, and the flow has a specific depth and drop for a specific flow rate, meaning that the energy dissipation rate on a stepped spillway depends on the water drop. The energy dissipation rate can be increased either by increasing the step height or by decreasing the flow rate in order to produce a 'stronger' drop. When water drops freely on to flat steps, it divides into two parts, one part flows towards the step edge (the 'front water') and generates a hydraulic jump, and the second part moves to the rear and hits the step raise ('back water'), causing turbulence in relation to the flow rate. Air entrainment increases and turbulence occurs when the backwater circulates.

In this study it was found that the energy dissipation rate on flat steps decreases with increasing flow rate. This could be because the backwater flow rate increases when the discharge increases as a result of the decrease in the gap or freeboard between the backwater surface and the bottom of the incoming jet. The backwater might then strike the incoming flow pushing it to the next step and reducing the opportunity for a hydraulic jump on the same step, see Fig. 7. Moreover, when the flow rate increases, the free fall disappears preventing both the hydraulic jump and turbulence.

The energy dissipation rate and the residual energy were both improved by the new step configuration, especially with reflector blocks and without the last step, see Figs. 5a \&b, and 6a \&b. This might have been because these new obstacles divided and disturbed the water more, and increased the air entrainment and hydraulic jump, as described in the section on flow patterns, see Fig. 3. These steps have a horizontal slope and curvature, therefore they disturb the flow more and have more reflector faces that direct water horizontally, 'organising' the flow over the steps. The new step configurations with reflectors dissipated energy more effectively than the new steps without reflectors, see Fig. $5 a$ \&b. They also reduced the residual energy at all flow rates, see Fig. $6 a$ \&b.

\subsection{Experimental Limitations}

First, while it is recognised that the results presented are valid for developing, non-aerated flow only in view of the scale of the model used, we nevertheless feel that it is valid to consider the general impact of the different configurations presented here. Aeration of the flow is likely to 
reduce friction on the spillway due to the presence of entrained air, which should be taken into account when scaling these results up to real spillways. It is also recognised that many of the comparative results from the literature cited here do take into account the impact of aerated flows. Nevertheless, the main idea of having these step configurations in this study was to cause a disturbance to the flow of water over steps by causing flow to split, generating turbulence in order to produce aerated flow. Turbulence was generated by both parts of flow, water circulated on the steps, and the water depth increased because of the air introduced into the water. Second, spillways are typically designed for high specific discharges, implying higher values of $y_{c} / h$ than those used here. Again we feel that it is nevertheless useful to describe the results we have as a means of comparing different step configurations in a controlled and measurable setting. Third, scale effects are certainly worthy of note in view of the relatively small model setup compared with a real spillway. The implications of these are discussed at some length in e.g., Pfister and Chanson (2014), in terms of common parameters such as Reynolds, Morton, and Weber numbers and the implications of these for laboratory spillway modelling. While we feel there would be some justification in giving consideration to these parameters in any detailed study leading to reproduction of these results at full scale, here we again stress the importance of gaining an understanding of the relative importance of the effects of spillway layout on energy dissipation, which we have attempted here.

\section{Conclusions}

Following a series of experiments carried out in a $0.3 \mathrm{~m}$ wide laboratory flume over a range of flow rates, it is clear that the rate of energy dissipation depends both on the flow rate itself but more importantly on the configuration of the steps. Rather than using a simple set of uniform steps it is recommended designers consider the possibility of using inclined and curved step configurations with reflectors to deal with unpredictable flow conditions. To the best of our knowledge, information on the performance these various different configurations is not widely available and further work should seek to build on these preliminary results.

The key findings from these experiments are as follows:

- There was a clear difference between the step configurations used in terms of the energy dissipation rate and residual energy, especially for flat steps with inclined and curved step configurations with reflectors.

- Energy dissipation rates decreased with increasing flow rate, and the residual energy increased with increasing flow rate for all step configurations, consistent with the results of previous studies. 
- The energy dissipation rate on horizontally inclined and curved step configurations with reflectors is about twice that for a flat step configuration.

- For a 26.6º stepped chute, designs with inclined and curved step configurations without reflectors do not provide much advantage in terms of energy dissipation and residual energy.

\section{Acknowledgements}

The authors would like to acknowledge the support of the University of Portsmouth for assisting in the funding of this project by providing the laboratory apparatus and technician support. The authors furthermore declare no conflict of interest of any kind in relation to any commercial or ethical considerations.

\section{References}

Boes, R., and Hager, W. (2003). Hydraulic Design of Stepped Spillways. Journal of Hydraulic Engineering, 129(9), 671-679.

Boes, R. (2000). Two phase flow and energy dissipation on cascades. (Doctor of Philosophy dissertation). Zurich: Switzerland

Bung, D.B. (2011). Developing flow in skimming flow regime on embankment stepped spillways. Journal of Hydraulic Research, 49(5), pp. 639-648.

Chamani, M., and Rajaratnam, N. (1999). Characteristics of Skimming Flow over Stepped Spillways. Journal of Hydraulic Engineering, 125(4), 361-368.

Chanson, H., and Toombes, L. (2001). Experimental Investigations of Air Entrainment in Transition and Skimming Flows down a Stepped Chute: Application to Embankment Overflow Stepped Spillways. Research Report No. CE158, Dept. of Civil Engineering, University of Queensland, Australia

Chanson, H., and Toombes, L. (2004). Hydraulics of Stepped Chutes: The Transition Flow. Journal of Hydraulic Research, 42(1), 43-54.

Chanson, H. (1994a) Hydraulics of Nappe flow regime above Stepped chutes and Spillways. Australian Civil Engineering Transactions, CE 36(1), 69-76

Chanson, H. (1994b) Hydraulics of Skimming Flows over Stepped Channels and Spillways. Journal of Hydraulic Research, 34(3), 445-460

Chanson, H. (1995).Hydraulic Design of Stepped Cascades, Channels, Weirs and Spillways. Oxford. Pergamon.

Chanson, H. (2001). A Transition Flow Regime on Stepped Spillways: The Facts. Retrieved from http://espace.library.uq.edu.au/eserv/UQ:11105/iahr001.pdf

Chinnarasri, C. (2002). Assessing the Flow Resistance of Skimming Flow on the Step Faces of Stepped Spillways. Dam Engineering, 12(4), 303-321. 
Chinnarasri, C., and Wongwises, S. (2004). Flow Regimes and Energy Loss on Chutes with Upward Inclined Steps. Canadian Journal of Civil Engineering, 31(5), 870-879.

Essery, I.T.S., and Horner, M.W. (1978). The hydraulic design of stepped spillways, CIRIA report 33

Felder, S., and Chanson, H. (2009). Energy Dissipation, Flow Resistance and Gas-liquid Interfacial Area in Skimming Flows on Moderate-slope Stepped Spillways. Environmental Fluid Mechanics. 9(4). 427-441.

Felder, S., and Chanson, H. (2011). Energy Dissipation down a Stepped Spillway with nonuniform Step Heights. Journal of Hydraulic Engineering, 137(11), 1543-1548.

Hazzab, A., and Chafi, C. (2006). Experimental Investigation of Flow and Energy Dissipation in Stepped Spillways. Larhyss Journal 5, 91-104

Mondardo, J. and Fabiani, A. (1995). Comparison of Energy dissipation between Nappe and Skimming Flow Regimes on Stepped Chutes. Journal of Hydraulic Research, 33(1), 119122.

Novak, P., Moffat, A., Nalluri, C., and Narayanan, R. (2007). Hydraulic Structures (4th ed.). Abingdon: Taylor \& Francis.

Ohtsu, I. and Yasuda, Y. (1997). Characteristics of Flow Conditions on Stepped Channels. Proceedings of 27th IAHR Congress, 10-15 August, San Francisco, USA.

Ohtsu, I., James, C., Matos, J., Yasuda, Y., Takahashi, M., Tatewar, S., Ingle, R., Porey, P., Chamani, M., and Rajaratnam, N. (2001). Onset of Skimming Flow on Stepped Spillways. Journal of Hydraulic Engineering,127(6), 519-525

Pfister M., and Chanson H. (2014). Two-Phase Air-Water Flows: Scale Effects in Physical Modeling. Journal of Hydrodynamics, 26(2), 291-298

Rajaratnam, N. (1990). Skimming Flow in Stepped Spillways. Journal of Hydraulic Engineering, 116(4), 587-591.

Sorensen, R.M. (1985). Stepped Spillway Hydraulic Model Investigation. Journal of Hydraulic Engineering, 111(12), 1461-1472

Thorwath J. and Köngeter J. (2006). Physical Model Test on a Stepped Chute with Pooled Steps - Investigation of Flow Resistance and Flow Instabilities. - International symposium on Hydraulic Structures, Caracas, Venezuela, 477 - 486

Toombes L. and Chanson H. (2008). Flow patterns in nappe flow regime down low gradient chutes, J Hydraul Res, 46 (1), 4-14

Yasuda, Y., Takahashi, M., and Ohtsu, I. (2001). Energy Dissipation of Skimming Flows on Stepped-channel Chutes. Proceedings of the 29th IAHR Congress, 16-21 September, Beijing, China. 


\section{Figure captions}

Figure 1. The five different forms of stepped spillway a) Flat stepped base model; b)Horizontally inclined steps $(\mathrm{h}=5 \mathrm{~cm}, \mathrm{I}=10 \mathrm{~cm}$ and $\mathrm{w}=29.6 \mathrm{~cm})$; c) Horizontally curved steps $(\mathrm{h}=5 \mathrm{~cm}, \mathrm{l}=$ $10 \mathrm{~cm}$ and $\mathrm{w}=29.6 \mathrm{~cm}) ; \mathrm{d})$ Inclined steps with reflector blocks $(\mathrm{h}=5 \mathrm{~cm}, \mathrm{l}=10 \mathrm{~cm}$ and $\mathrm{w}=29.6$ $\mathrm{cm})$; e) Curved steps with reflector blocks $(\mathrm{h}=5 \mathrm{~cm}, \mathrm{l}=10 \mathrm{~cm}$ and $\mathrm{w}=29.6 \mathrm{~cm}$ )

Figure 2. Flow regimes on flat steps (a) Nappe Flow (b) Transitional Flow (c) Skimming Flow Figure 3 New step configuration dividing the water on a stepped spillway.

Figure 4. Energy dissipation rate at the downstream end of flat stepped chutes: comparison with previous studies

Figure 5. (a) Relative energy loss on all step configurations (b) Relative energy loss on all step configurations without the last step

Figure 6. (a) Residual energy downstream of all step configurations (b) Residual energy downstream of all step configurations without the last step

Figure 7. Water profile on flat step 


\begin{tabular}{|l|l|l|l|l|}
\hline No. & Study & \multicolumn{2}{|l|}{$\mathrm{yc}_{\mathrm{c}} / \mathrm{h}$} & \\
\cline { 3 - 5 } & & Nappe (NA) & Transition (TRA) & Skimming (SK) \\
\hline 1 & Chanson, 1994a \&b & 0.038 & & 0.965 \\
\hline 2 & Chanson, 2001 & 0.690 & & \\
\hline 3 & Yasuda et al., 2001 & 1.371 & & \\
\hline 4 & Chinnarasri, 2002 & 0.727 & & \\
\hline 5 & $\begin{array}{l}\text { Chinnarasri \& } \\
\text { Wongwises, 2004 }\end{array}$ & 0.294 & & 0.506 \\
\hline 6 & $\begin{array}{l}\text { Hazzab \& Chafi, } \\
2006\end{array}$ & 0.670 & & 0.670 \\
\hline 7 & $\begin{array}{l}\text { Ohtsu \& Yasuda, } \\
1997\end{array}$ & & $0.729-0.966$ & \\
\hline 8 & $\begin{array}{l}\text { Chanson \& Toombes, } \\
2004\end{array}$ & & $0.727-0.960$ & \\
\hline 9 & Rajaratnam, 1990 & & & 0.800 \\
\hline 10 & $\begin{array}{l}\text { Mondardo \& Fabiani, } \\
1995\end{array}$ & & & 0.899 \\
\hline 11 & Ohtsu et al., 2001 & & & 0.962 \\
\hline 12 & Boes, 2000 & & & \\
\hline 13 & \begin{tabular}{l} 
Current study \\
\hline
\end{tabular} & 0.666 & $0.666<$ T >1.108 & 1.108 \\
\hline
\end{tabular}

Table 1 Comparison of flow regimes for the flat stepped spillway of this study with upper and lower limits of flow regimes on flat stepped spillways used in previous studies. Some results were calculated in this study from empirical equations, and others were quoted by Hazzab and Chafi (2006). 
a)

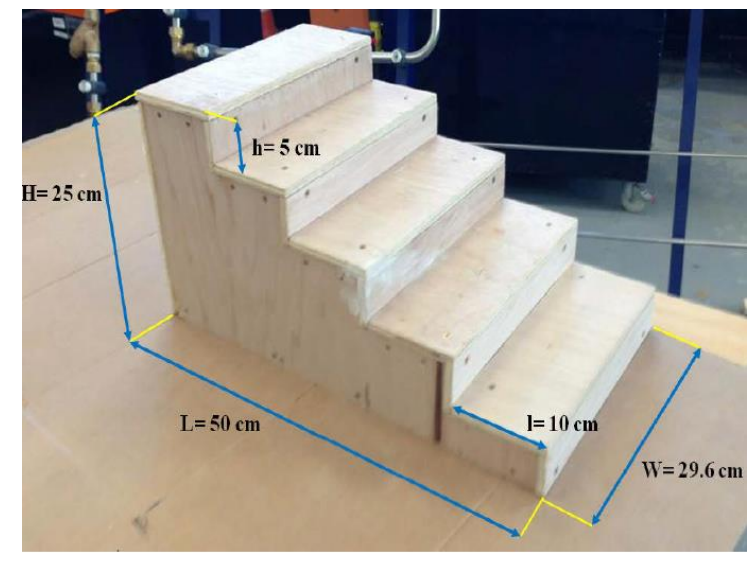

b)

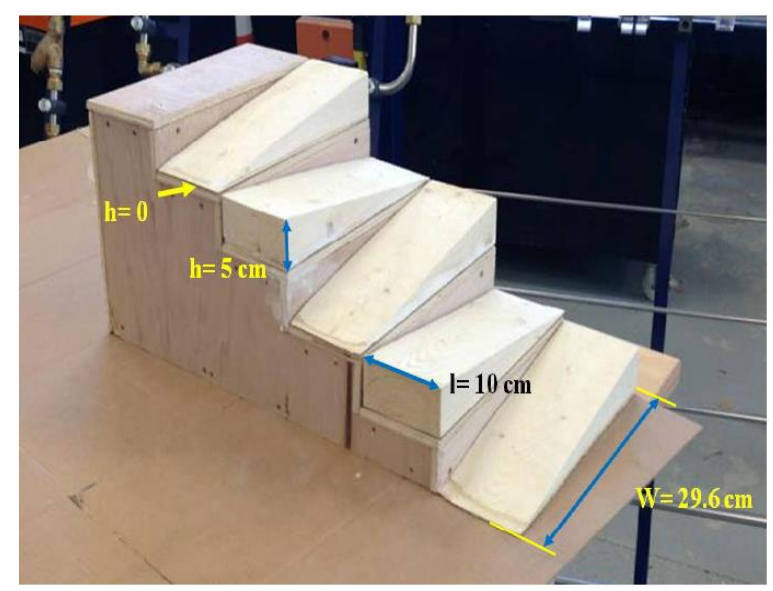

c)

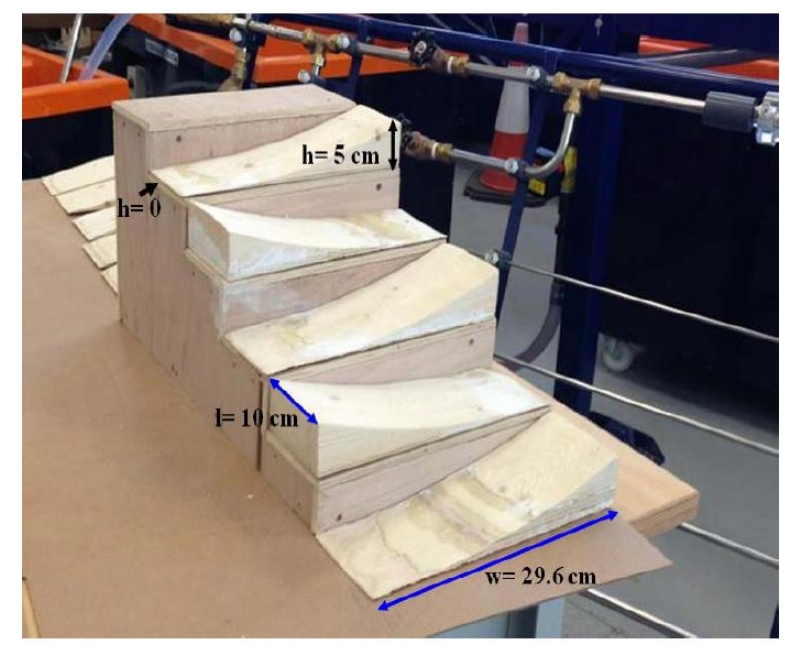


d)

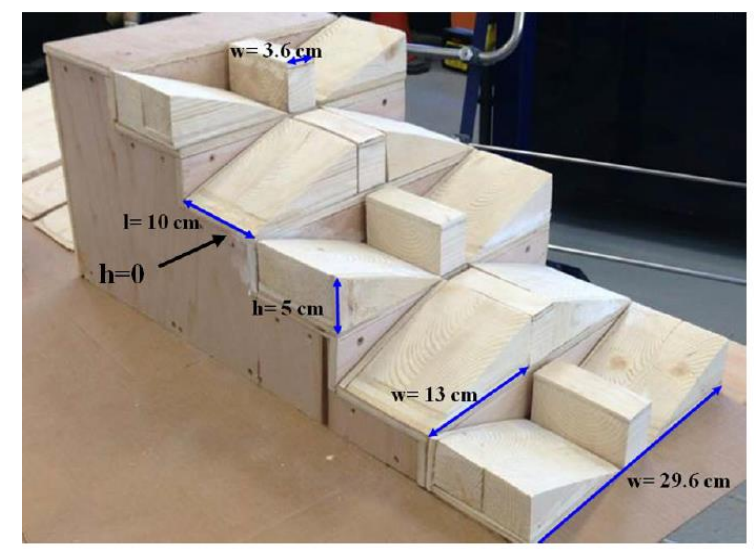

e)

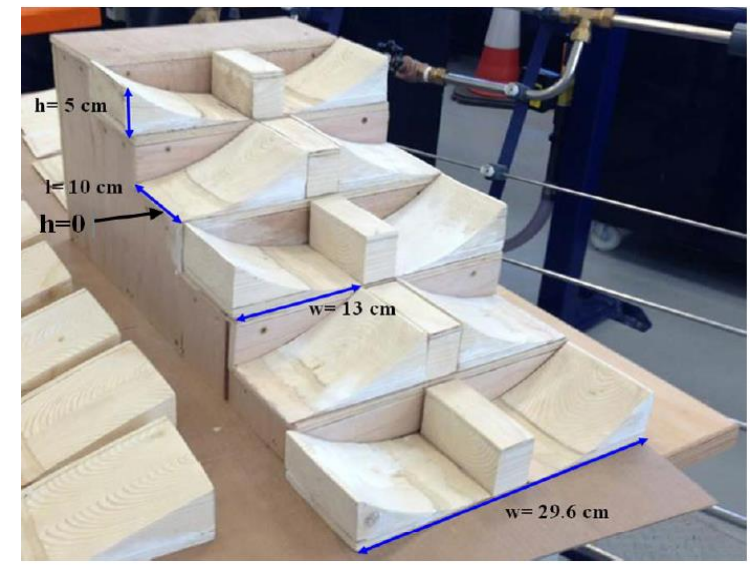

FIGURE 1 
a)

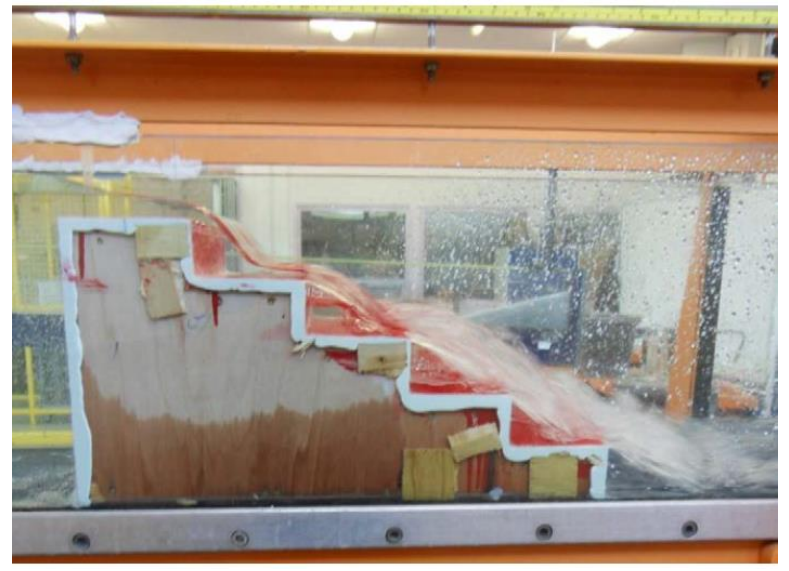

b)

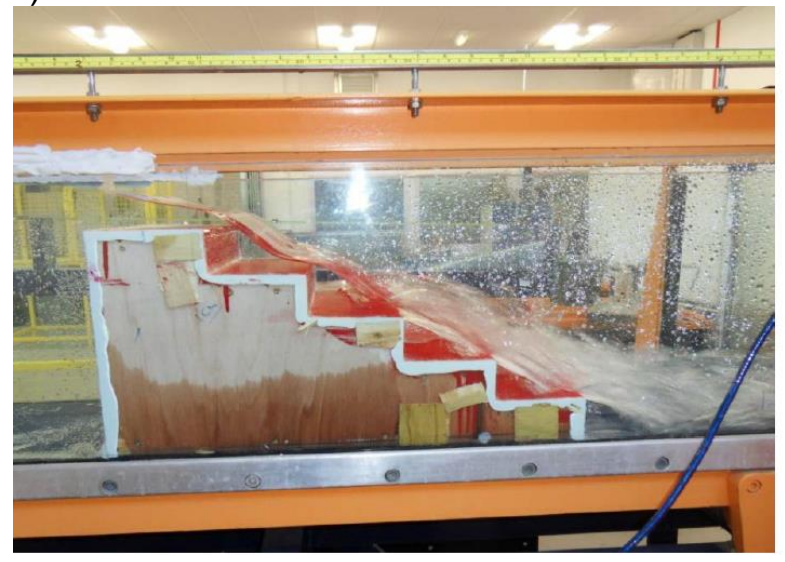

c)

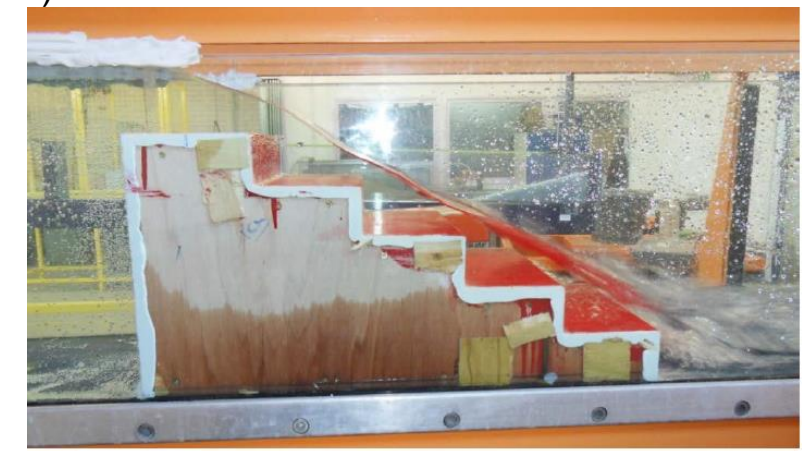

FIGURE 2 


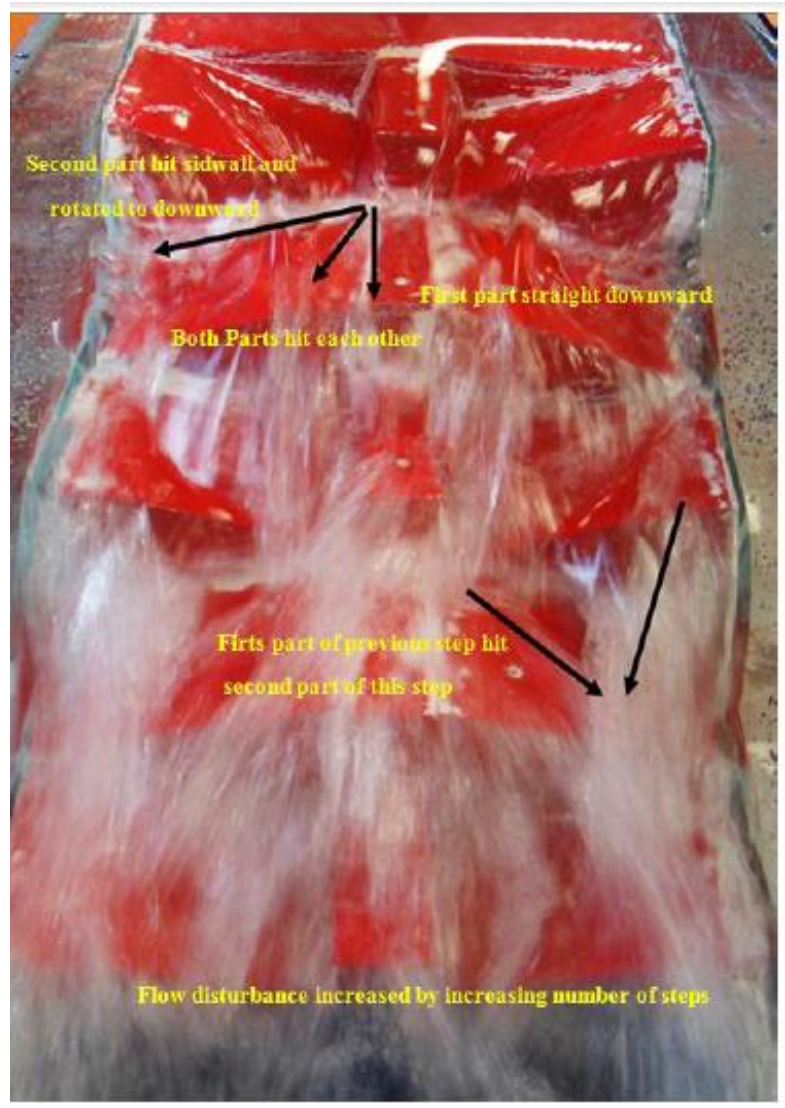

FIGURE 3 


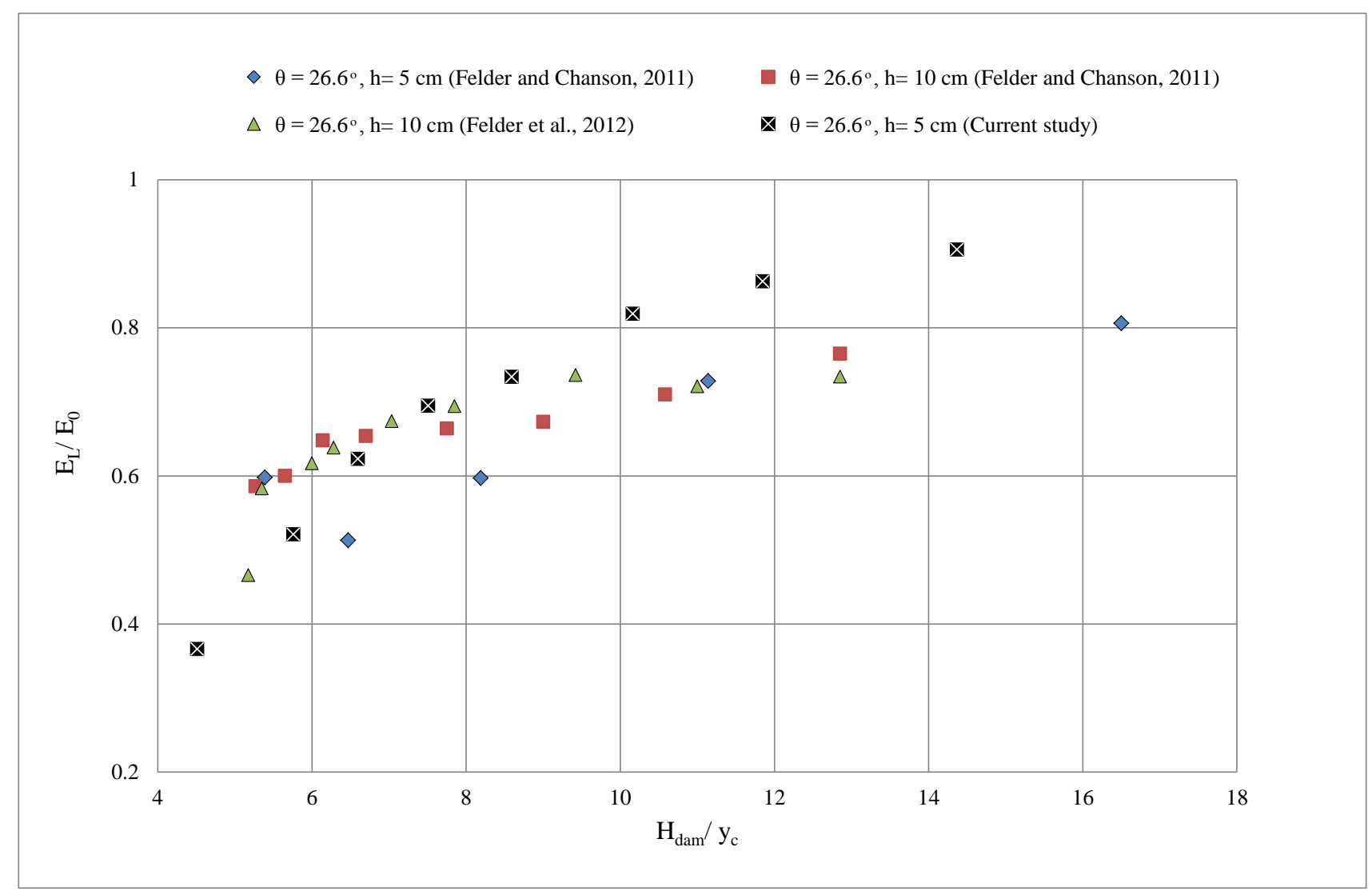

FIGURE 4 
a)

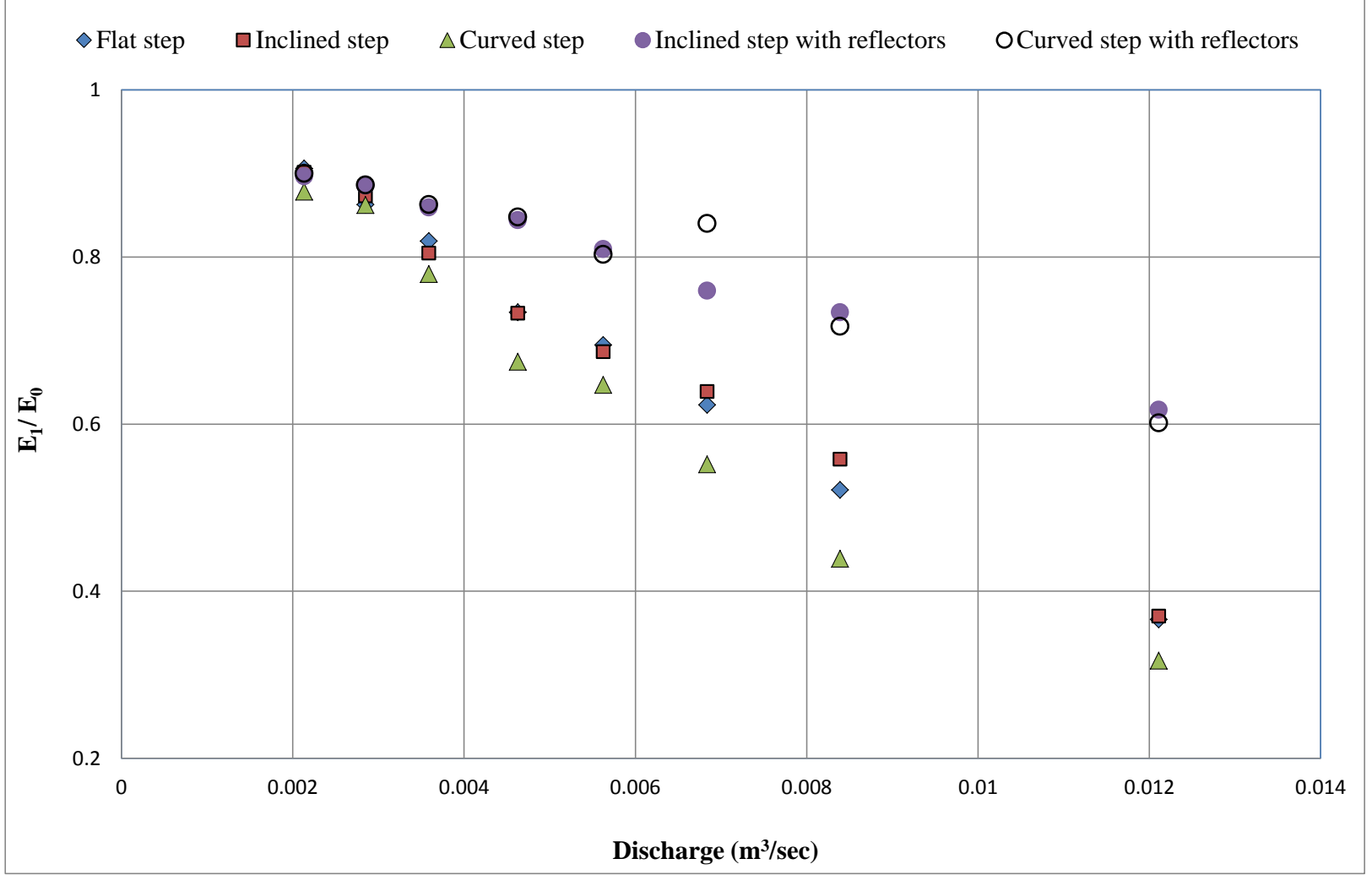

b)
$\diamond$ Flat step
Inclined step without last step
$\triangle$ Curved step without last step
- Inclined step with reflectors and without last step

○ Curved step with reflectors and without last step

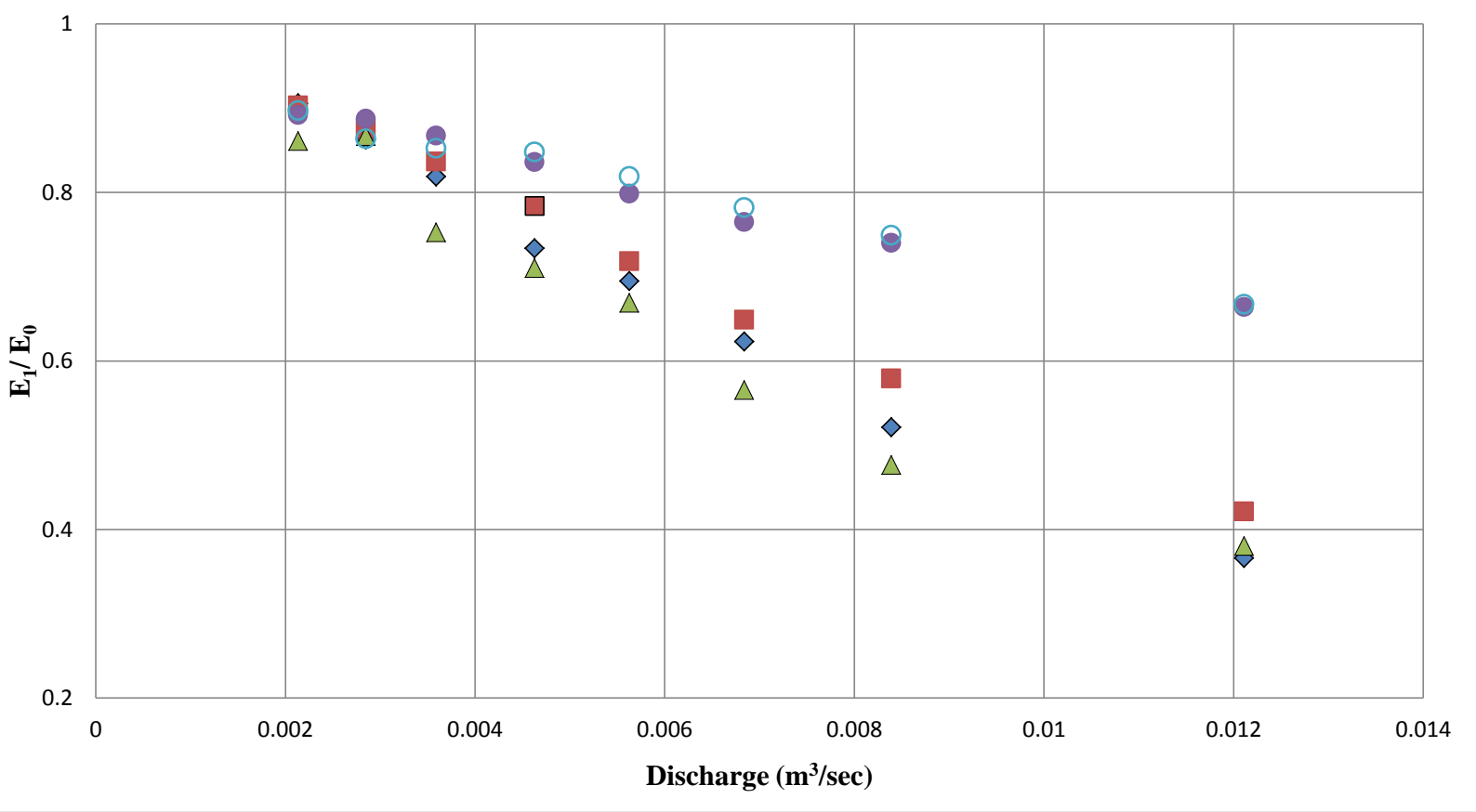

FIGURE 5 
a)

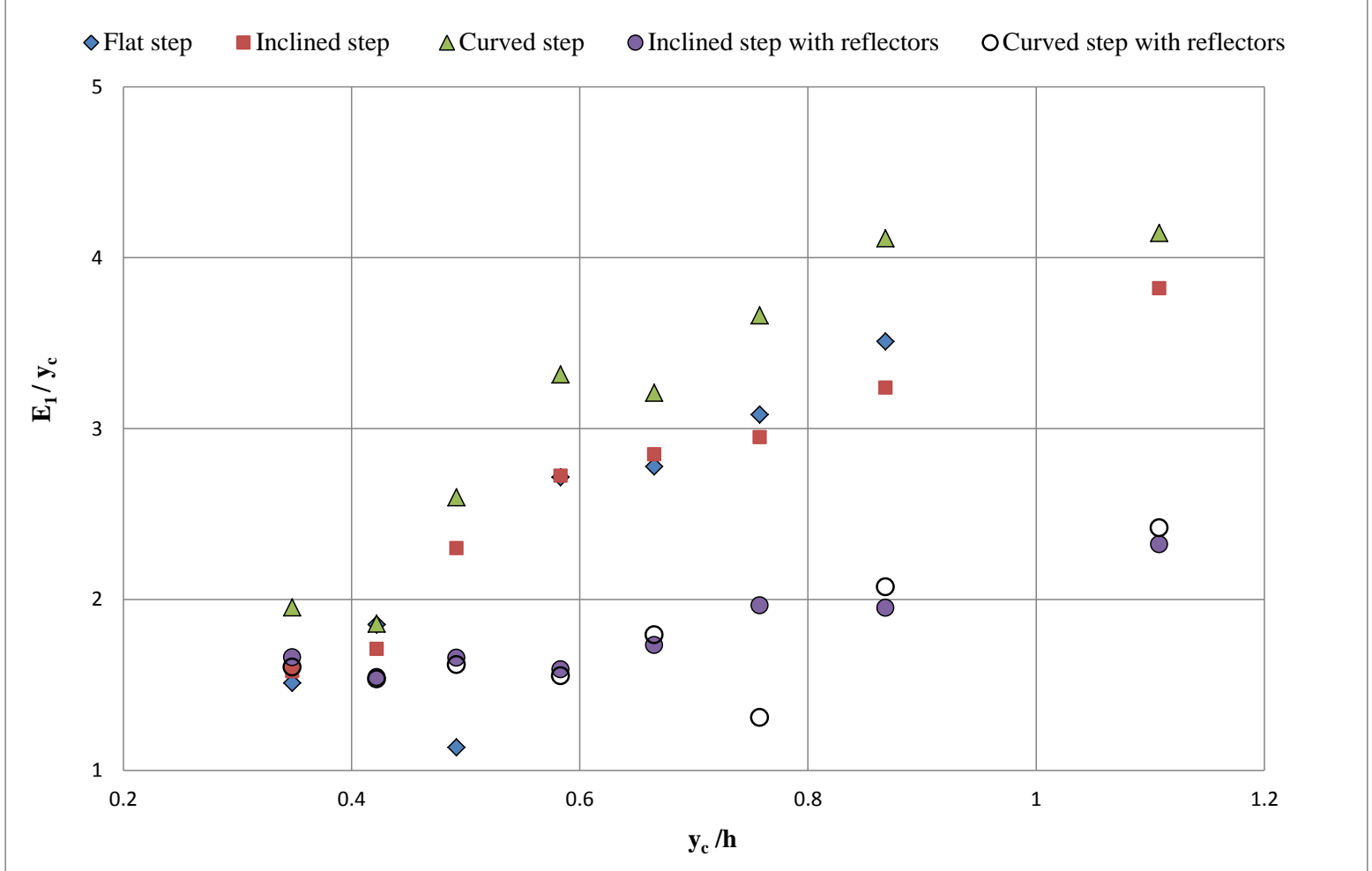

b)

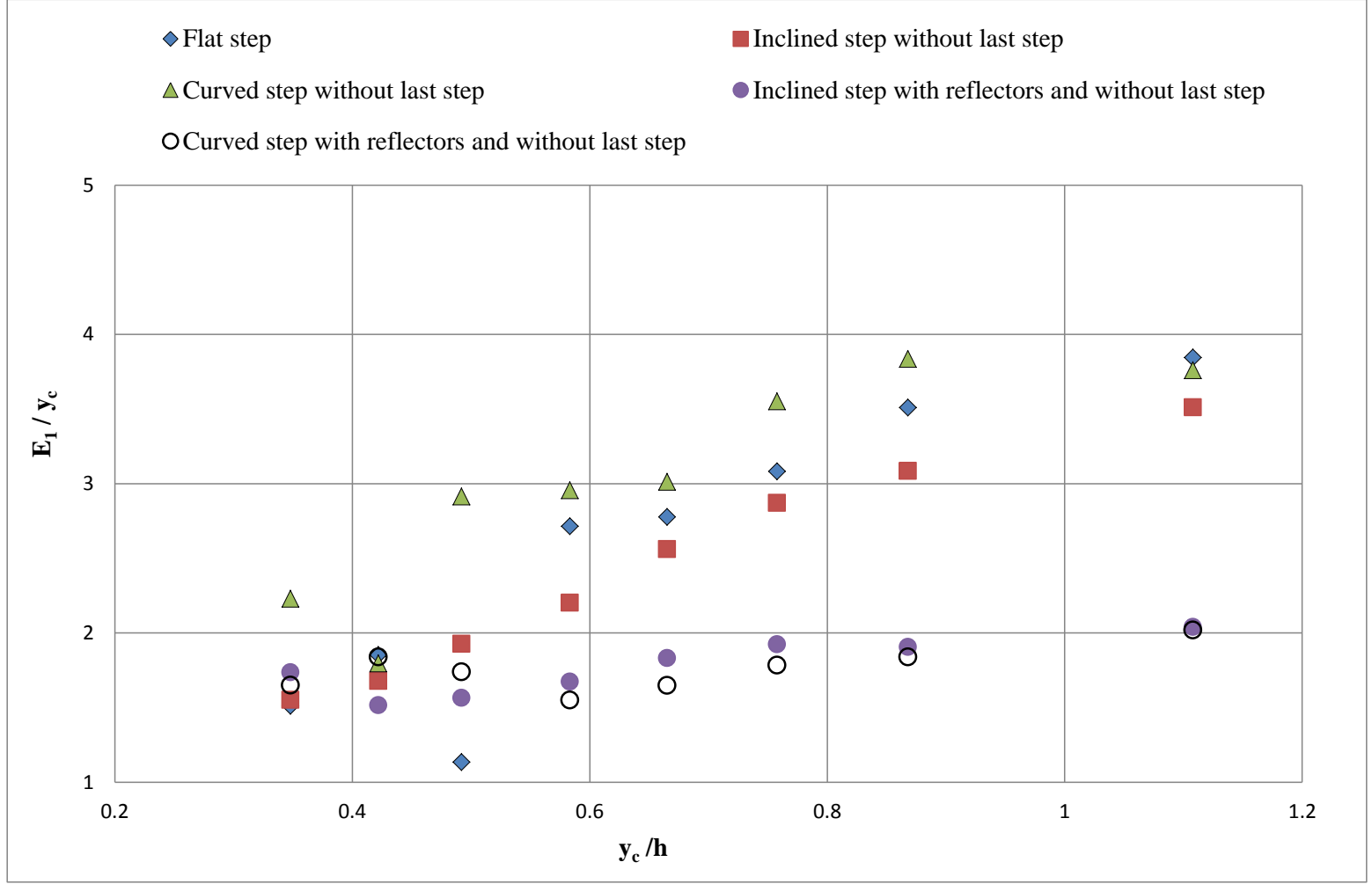

FIGURE 6 


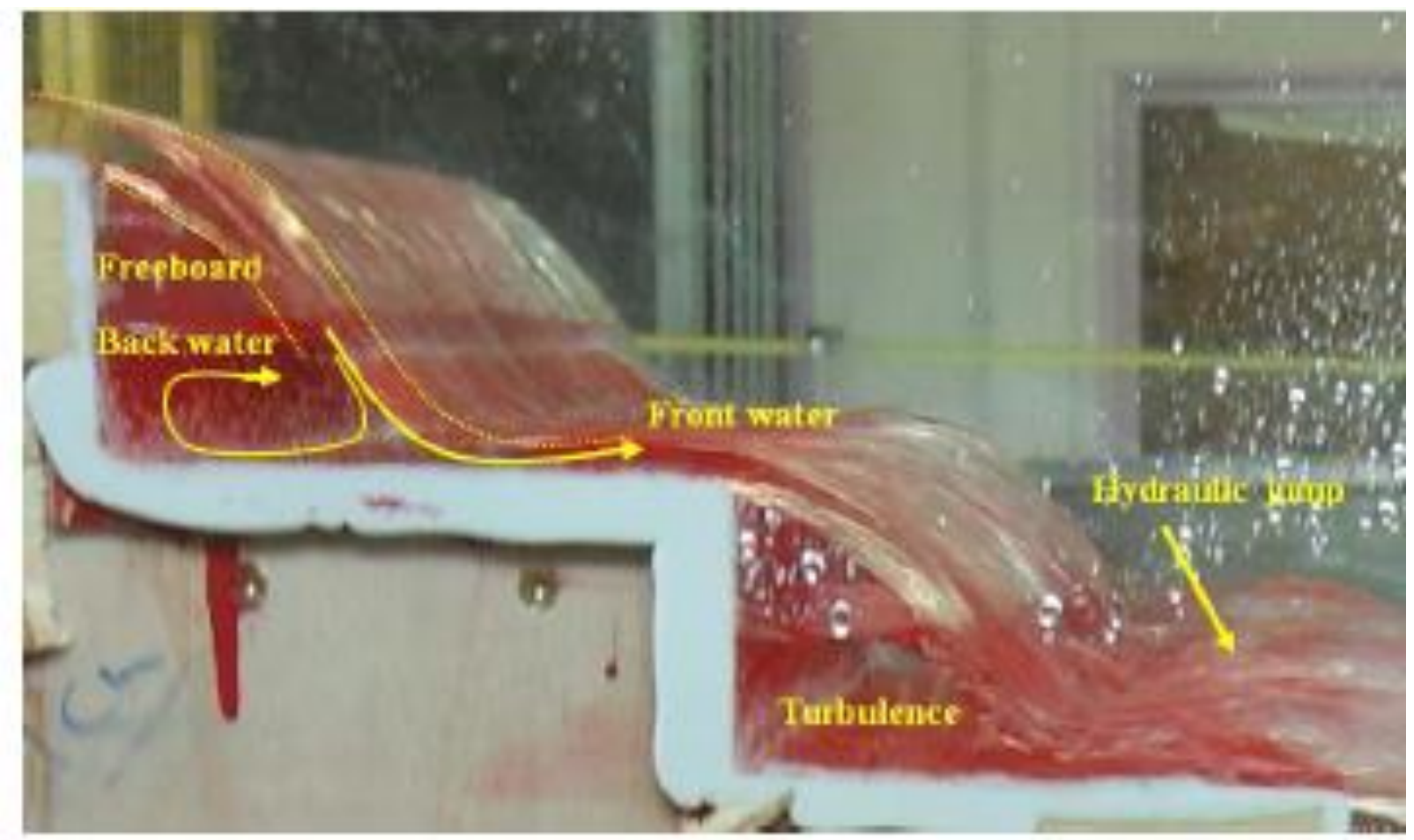

FIGURE 7 
